\title{
Prevalence of Hypertension and Adherence to Dietary Approaches to Stop Hypertension Diet Score in Childbearing Age Tunisian Women: A Cross-Sectional Study
}

\author{
Jalila El Ati $\mathbb{D}^{1},{ }^{1}$ Radhouene Doggui $\mathbb{D}^{1},{ }^{1}$ Houda Ben Gharbia $\mathbb{D}^{1},{ }^{1}$ and Myriam El Ati-Hellal $\mathbb{D}^{2}$ \\ ${ }^{1}$ INNTA (National Institute of Nutrition and Food Technology), SURVEN (Nutrition Surveillance and Epidemiology in Tunisia) \\ Research Laboratory, 11 Rue Jebel Lakhdar, Bab Saadoun, 1007 Tunis, Tunisia \\ ${ }^{2}$ IPEST (Preparatory Institute for Scientific and Technical Studies), Laboratory Materials Molecules and Applications, \\ University of Carthage, P.B. 51, 2070 Tunis, Tunisia
}

Correspondence should be addressed to Myriam El Ati-Hellal; mfh22002@yahoo.fr

Received 23 October 2020; Revised 11 June 2021; Accepted 28 October 2021; Published 5 November 2021

Academic Editor: Yao Jie Xie

Copyright (c) 2021 Jalila El Ati et al. This is an open access article distributed under the Creative Commons Attribution License, which permits unrestricted use, distribution, and reproduction in any medium, provided the original work is properly cited.

Background and Aims. The prevalence, awareness, and treatment of hypertension, along with their sociodemographic, anthropometric, and lifestyle associations, were evaluated in a cross-sectional survey of childbearing age Tunisian women. Adherence to the Dietary Approaches to Stop Hypertension diet score was also assessed for hypertensive versus nonhypertensive women. Methods and Results. A total of 1689 nonpregnant women, aged 20-49 years, were randomly sampled a regional (Greater Tunis), two-stage, stratified, cross-sectional cluster survey from March 2009 to January 2010. Data on medical history and sociodemographic characteristics were collected using a questionnaire. The average daily intake of energy and nutrients was computed using a specific Tunisian food composition database. The Dietary Approaches to Stop Hypertension diet score (0 to 10$)$ was assessed by adding the individual scores ( 0 to 1$)$ of ten nutrient components according to dietary guidelines. The overall prevalence of hypertension was $21.4 \%$. Age, obesity, abdominal fat, parity, and family history were significantly associated with hypertension. The mean Dietary Approaches to Stop Hypertension accordance score was 4.93 for hypertensive women and 4.86 for nonhypertensive women $(P=0.0556)$. After adjustment for age, energy intake, and all nutritional covariates, no associations were observed between hypertension and Dietary Approaches to Stop Hypertension diet components. Conclusion. Though no clear-cut associations between hypertension and environmental or behavioral factors were identified in the study, the association with abdominal obesity and multiparity suggests that interventions aimed at lifestyle modifications to reduce these risk factors could be also useful in the prevention of hypertension.

\section{Introduction}

Noncommunicable diseases account for almost $71 \%$ of deaths throughout the world [1]. Hypertension (HTN) is a chronic disorder characterized by a persistently raised pressure in blood vessels. Globally, HTN is a major public health problem as it is the leading cause of cardiovascular diseases and is responsible for 9.4 million deaths each year in the world [2]. The prevalence of HTN is the highest in the African continent where it affects $46 \%$ of adults aged $25 \mathrm{y}$ and over.

The emergence of HTN could be attributed to demographic growth and population ageing, rising urbanization, inadequate health care systems, and lifestyle changes [3-5]. Within these risk factors, poor diet is the major driver for noncommunicable diseases [6]. Hence, adherence to healthy dietary patterns is an important component for the prevention of HTN. The Dietary Approaches to Stop Hypertension (DASH) emphasized fruits, vegetables, nuts, whole grains, and low-fat dairy products and is based on lowering the consumption of sugary and sweetened beverages, sweets, and red and processed meat $[7,8]$. The consumption of DASH dietary pattern was found to be protective against cardiovascular diseases, to reduce coronary heart diseases and diabetes incidence with a risk reduction of about $20 \%$ [9]. Besides, in 
a recent meta-analysis made by Soltani et al. (2020), it was reported that an increase of adherence to DASH patterns by an increment of 5 points reduces the risk of mortality by cardiovascular diseases, stroke, and cancer [10].

Tunisia is a Middle East and North African (MENA) country with eleven million inhabitants, located between Algeria in the east and Libya in the south. The high level of development $\left(91^{\text {st }}\right.$ out of 189 nations in 2019 on the Human Development Index) [11] is unevenly distributed, higher in the main cities and the eastern coastal regions, due to urbanization, prosperous industrial, and tourist activities. Tunisia has experienced during the last three decades a nutrition transition characterized by the emergence of overweight and obesity among all age classes [12]. A significant gender difference was found, with a higher prevalence of overweight among adult women [13]. Consistently, a diet westernization occurred characterized by the emergence of fast food and high energy and poor nutrient food consumption [14]. Consequently, chronic noncommunicable diseases progressed among younger adults, as, for example, diabetes increased from $8.6 \%$ among adult women (35-44y.) in 1996 to 11.8 in 2005 [15].

This study is aimed at assessing the prevalence, awareness, and treatment of HTN among childbearing age Tunisian women and its association with the sociodemographic, anthropometric, and lifestyle factors. The accordance of hypertensive and nonhypertensive women to Dietary Approaches to Stop Hypertension (DASH) diet guidelines was also evaluated to have an idea on the impact of DASH diet on HTN in Tunisia [7, 16-18].

\section{Methods}

2.1. Setting. Tunisia is an upper-middle-income North African country (Human Development Index in 2010 was 0.683). The survey was carried out in the Great Tunis region, which is formed by four governorates, namely, Tunis, Ariana, Ben Arous, and Manouba. The Greater Tunis is mainly urban area where is living 2.5 million inhabitants in 2010 (92\% live in urban settings).

2.2. Subjects and Study Design. The target population for the present study was all women aged between 20 and $49 \mathrm{y}$ nonpregnant and living in Greater Tunis. The only exclusion criterion was pregnancy. In the framework of the Obe-Maghreb research project $[19,20]$, a cross-sectional survey was carried out from March 2009 to January 2010 using a two-stage random cluster sampling design of households [21].

2.2.1. Sample Size Calculation. The calculation of sample size was carried out by the National Institute of Statistics. As the statistical unit for the survey was the household, the calculation of the sample size of households $(n)$ with women aged 20-49y was done using the following formula: $n=t^{2} \times p \times(1-p) \times D E F F \times\left(1 / d^{2}\right)$.

The calculation of the sample was based on the prevalence of double burden obesity and anaemia $(P=11.8 \%)$ among females aged 20 to $49 \mathrm{y}$. By setting a precision $(d)$ of $3 \%$, a margin of error of $5 \%$, a cluster effect (DEFF) of
3 , and a refusal rate of $5 \%$ and knowing that the population of women aged 20 to $49 y$ represented about $23 \%$ of the total population (according to the census of 2004) and that the average household size is equal to 4.53 , the number of households required would be equal to 1520 .

2.2.2. Sampling and Recruitment Procedure. Households were selected using a stratified two-stage random sampling: stratification was according to the 4 governorates. In each stratum, at the first sampling stage, primary units (referred to as census districts) were selected with a probability based on the census district's size and with 76 districts in all. At the second stage, in each district, 20 households were randomly selected, and all members aged 6 months to 49 years were included in the sample. We used the subsample of $20-49 \mathrm{y}$ nonpregnant women.

\subsection{Data Collection and Measurements}

2.3.1. Blood Pressure. Blood pressure (BP) was measured twice with calibrated sphygmomanometers (Vaquez Laubry type, Spengler, France). The estimation of BP was based on the average of the two readings. HTN was defined as average systolic BP (SBP) and/or diastolic (DBP) levels $=140 / 90$ mmHg [19].

2.3.2. Dietary Intake and DASH Score. Dietary intake was assessed using a 3-day food record (two weekdays and one weekend day) to collect the types and amounts of the meals, foods, and beverages consumed [20]. The first step of the 3-day food record was self-administered by the subjects at home. In the day of the survey, trained dieticians reviewed unclear descriptions, errors, or omissions in the filled preprinted form and checked them with participants. For each dish, a list of ingredients, the estimated weight of the raw edible portion, and the method of preparation were collected. The accuracy of portion size of consumed foods was checked using household measures, photos of food portions [21], and known weight/specific portions.

To calculate the DASH score, food items were regrouped into 10 food groups: total grain; vegetables; fruits; dairy products; meats, poultry, and fish; nuts, seeds, dry beans, and sweets [22]. These components were chosen to achieve the DASH diet target, which is the reduction of blood pressure with a high intake of fruits, vegetables, legumes, seeds, and low-fat dairy products and whole grains and a low intake of sodium, total and saturated fats, cholesterol, and added sugars [16, 17, 22-24]. The score of each component varies from 0 tol and the DASH accordance score is obtained by adding scores of the ten nutrient components. Then, a total nonaccordance to the DASH diet guidelines is represented by a score of 0 while a score of 10 indicates a total accordance to DASH guidelines. This scoring system was developed previously [23].

The nutritional profile of the recipes was calculated by applying to the edible part raw ingredients, yield factors to account for the change in weight during cooking, and retention factors to account for changes in their nutritional content [25]. The Tunisian food composition table [26], supplemented by the USDA table [27], additional laboratory 
analyses, and the Food Processor software, version 8.3 [28], were used to estimate the energy and nutritional content (macro- and micronutrients) of the consumed food items. We defined implausible energy intakes as $<500$ or $>3500 \mathrm{kcal} / \mathrm{d}$ for women [29]. No case had been excluded.

2.3.3. Covariates. Data on the level of education, profession, medical history, parity, and household socioeconomic status were collected by trained field agents using a standardized measurement protocol and questionnaire.

2.3.4. Anthropometry. Body weight was measured to the nearest $0.1 \mathrm{~kg}$ using a digital scale, and height was measured to the nearest $0.1 \mathrm{~cm}$ with a stadiometer. Body mass index (BMI) (= weight $/$ height $\left.^{2}\right) \geq 25 \mathrm{~kg} / \mathrm{m}^{2}$ defined overweight and $\mathrm{BMI} \geq 30 \mathrm{~kg} / \mathrm{m}^{2}$ obesity [30]. To assess abdominal fat, waist circumference (WC) was measured to the nearest $0.1 \mathrm{~cm}$ using a nonelastic metric measuring tape. $W C \geq 80 \mathrm{~cm}$ defined "increased risk abdominal obesity" and WC $\geq 88 \mathrm{~cm}$ "high risk abdominal obesity" [30].

2.3.5. Tobacco. Current smokers of cigarettes were those who had smoked in the past one month (cigarettes, chichi, Neffa).

2.3.6. Sports. Physical activity of subjects during the 7 days preceding the survey was assessed using a validated frequency questionnaire [31]. Sport activities were scored "yes" for women who regularly carry out a sport activity and "no" for women who do not exercise at all any sport.

2.4. Data Management and Statistical Analysis. Data entry screens including quality checks as well as validation by double-entry used EpiData Software version 3.1 (The Epidata Association, Odense, Denmark, 2008). Data management was performed using the Stata software version13.0 (Stata Corporation, College Station, Texas, 2013) software. Results are shown as mean \pm standard error. The association between categorical variables was evaluated by the test of chi-square. The odds ratio (OR) of being hypertensive in association with covariates was assessed using logistic regression. To control for potential confounding due factors, we adjusted for the socioeconomic and demographic characteristics after the selection of an appropriate reference category. For testing and confidence intervals, alpha 5\% threshold was chosen.

2.5. Ethical Consideration. The Ethical Committee of the Tunisian National Institute of Nutrition and Food Technology and the Tunisian National Council of Statistics approved the survey protocol (visa ${ }^{\circ} 2 / 2009$ ). After being informed about the purpose and procedures of the survey, all participants gave their consent to take part in the study, which was held at primary health-care centers and hospitals. This study is also registered in the ClinicalTrials.gov registry. The Identifier number is NCT01844349.

\section{Results}

3.1. Sample Characteristics. Of the 1887 eligible nonpregnancy women aged 20-49y, 1689 were involved in the analyses, yielding an overall response rate of $89.5 \%$. The mean age women included in the study was $36.1 \pm 0.3 \mathrm{y}$ and mean BMI $28.3 \pm 0.2 \mathrm{~kg} / \mathrm{m}^{2}$. Two-thirds of women were married, and more than one-third had no children. Only one-tenth of women had never attended school, and onethird worked outside the home.

3.2. Prevalence of HTN. Table 1 provides the estimated prevalence and adjusted associations of HTN by sociodemographic characteristics and lifestyle factors. Overall, $21.4 \%$ of childbearing age Tunisian women were hypertensive. The prevalence of HTN increased significantly with age, BMI, and WC. HTN was more prevalent $(P<0.0001)$ among married women $(25.9 \%)$ in comparison with single, divorced, or widowed ones (12.3\%). A greater prevalence of HTN was observed in women with 3 children or more (30.0\%) as compared with women without children (10.9\%) or with one or two children (21.4\%). Menopausal women were more hypertensive than premenopausal (40.2\% vs. $25.0 \%$; $P=0.0011)$. The prevalence of HTN was higher among illiterate group compared to intermediate or higher education level groups. The area of living as well as the household size and the economic level had no influence on the prevalence of HTN in women. As regards lifestyle factors, no significant differences in smoking habits and physical activity were noticed (Table 1). HTN was more frequent for women who reported a family history of HTN. Among the total hypertensive subjects, $29.6 \%$ were aware of their situation, and almost the fifth was on antihypertensive treatment. Sixty-five percent of hypertensive women, who were aware of their condition, were receiving treatment.

After adjustment for all socioeconomic, anthropometric, and behavioral covariates, the prevalence of HTN increased markedly with age $(\mathrm{OR}=2.90[1.25-7.50] ; P=$ $0.034)$, obesity $(\mathrm{OR}=1.61[1.15-3.06] ; P=0.014)$, highrisk abdominal obesity $(\mathrm{OR}=2.76[1.47-5.18] ; P=0.002)$, parity $(\mathrm{OR}=2.02[1.09-3.76] ; P=0.027)$, and family history of HTN $(\mathrm{OR}=1.77[1.24-2.53] ; P=0.002)$.

3.3. DASH Score. Table 2 presents a comparison of the accordance to DASH diet guidelines between hypertensive and nonhypertensive women. Significant differences were observed for total grain, sweets, and sodium intake. Hypertensive women achieved the highest score for total grain intake $(81.6 \%$ of hypertensive women vs. $71.5 \%$ of nonhypertensive women; $P=0.041$ ), whereas nonhypertensive women had better adherence to the DASH diet guidelines for sweets and sodium intake. The mean DASH accordance score, obtained after the addition of the different component scores, was 4.93 for hypertensive women and 4.86 for nonhypertensive women $(P=0.0556)$.

\section{Discussion}

In the present study, we found significant associations between HTN and age, BMI, WC, parity, and family history of HTN. After considering potential confounders, these significant associations were also present except for WC factor. Besides, the adherence to DASH diet score was elevated for 
TABLE 1: Prevalence and adjusted odds ratio of HTN by sociodemographic characteristics, body mass index, waist circumference, and lifestyle factors.

\begin{tabular}{|c|c|c|c|c|c|}
\hline \multirow[b]{2}{*}{ Variables } & \multirow[b]{2}{*}{$N$} & \multicolumn{4}{|c|}{ HTN } \\
\hline & & $\%^{1}$ & $P^{2}$ & $\begin{array}{l}\text { Adjusted } \mathrm{OR}^{3} \\
\text { (CI 95\%) }\end{array}$ & $P^{4}$ \\
\hline \multicolumn{6}{|l|}{ Age (year) } \\
\hline 20-29 & 509 & 8.7 & \multirow{3}{*}{$<0.0001$} & 1 (ref) & \\
\hline $30-39$ & 496 & 18.1 & & $0.45(0.02-8.64)$ & 0.60 \\
\hline $40-49$ & 684 & 33.0 & & $2.90(1.25-7.50)$ & 0.034 \\
\hline \multicolumn{6}{|l|}{ Body mass index $\left(\mathrm{kg} / \mathrm{m}^{2}\right)$} \\
\hline$<25$ & 524 & 8.0 & \multirow{3}{*}{$<0.0001$} & 1 (ref) & \\
\hline $25-29$ & 555 & 17.9 & & $0.92(0.51-1.68)$ & 0.79 \\
\hline$\geq 30$ & 610 & 35.5 & & $1.61(1.15-3.06)$ & 0.014 \\
\hline \multicolumn{6}{|l|}{ Waist circumference $(\mathrm{cm})$} \\
\hline$<88$ & 487 & 7.6 & \multirow{3}{*}{$<0.0001$} & 1 (ref) & \\
\hline $88-102$ & 391 & 13.4 & & $1.27(0.72-2.23)$ & 0.40 \\
\hline$\geq 102$ & 811 & 33.3 & & $2.76(1.47-5.18)$ & 0.002 \\
\hline \multicolumn{6}{|l|}{ Marital status } \\
\hline Single, divorced, or widowed & 608 & 12.3 & \multirow{2}{*}{$<0.0001$} & 1 (ref) & \\
\hline Married & 1081 & 25.9 & & $0.77(0.46-1.27)$ & 0.30 \\
\hline \multicolumn{6}{|l|}{ Parity } \\
\hline 0 & 621 & 10.9 & \multirow{3}{*}{$<0.0001$} & 1 (ref) & \\
\hline 1 or 2 & 495 & 21.4 & & $1.60(0.83-3.07)$ & 0.15 \\
\hline 3 and more & 573 & 30.0 & & $2.02(1.09-3.76)$ & 0.027 \\
\hline \multicolumn{6}{|l|}{ Menopause } \\
\hline No & 1552 & 21.4 & \multirow{2}{*}{0.0011} & 1 (ref) & \\
\hline Yes & 137 & 40.2 & & $1.49(0.97-2.29)$ & 0.067 \\
\hline \multicolumn{6}{|l|}{ Level of instruction } \\
\hline Secondary and graduate & 894 & 16.9 & \multirow{3}{*}{0.0001} & 1 (ref) & \\
\hline Primary & 613 & 25.2 & & $1.10(0.64-1.88)$ & 0.73 \\
\hline No schooling & 182 & 30.6 & & $1.02(0.72-1.43)$ & 0.93 \\
\hline \multicolumn{6}{|l|}{ Professional activity } \\
\hline Yes & 564 & 17.8 & \multirow{2}{*}{0.014} & 1 (ref) & \\
\hline No & 1125 & 23.1 & & $1.29(0.93-1.80)$ & 0.13 \\
\hline \multicolumn{6}{|l|}{ Area of living } \\
\hline Rural & 214 & 15.6 & \multirow{2}{*}{0.22} & 1 (ref) & \\
\hline Urban & 1474 & 21.8 & & $1.68(0.81-3.46)$ & 0.16 \\
\hline \multicolumn{6}{|l|}{ Household size } \\
\hline $1-4$ & 687 & 22 & & 1 (ref) & \\
\hline 5 & 480 & 21.1 & 0.91 & $0.69(0.43-1.10)$ & 0.11 \\
\hline 6 and + & 522 & 21.1 & & $0.71(0.46-1.10)$ & 0.13 \\
\hline Household economic level & & & & & \\
\hline High & 576 & 22.2 & & 1 (ref) & \\
\hline Middle & 553 & 22.4 & 0.53 & $1.37(0.87-2.15)$ & 0.17 \\
\hline Low & 560 & 19.6 & & $1.22(0.80-1.85)$ & 0.34 \\
\hline Sport activity & & & & & \\
\hline Yes & 114 & 21.2 & 062 & 1 (ref) & \\
\hline No & 1575 & 23.3 & 0.02 & $1(0.22-1.01)$ & 0.056 \\
\hline Smoking tobacco & & & & & \\
\hline Nonsmoker & 1568 & 21.9 & 027 & 1 (ref) & \\
\hline Current smoker & 121 & 13.0 & 0.27 & $0.53(0.26-1.08)$ & 0.079 \\
\hline
\end{tabular}


TABLE 1: Continued.

\begin{tabular}{|c|c|c|c|c|c|}
\hline \multirow[b]{2}{*}{ Variables } & \multirow[b]{2}{*}{$N$} & \multicolumn{4}{|c|}{ HTN } \\
\hline & & $\%^{1}$ & $P^{2}$ & $\begin{array}{l}\text { Adjusted } \mathrm{OR}^{3} \\
\text { (CI 95\%) }\end{array}$ & $P^{4}$ \\
\hline \multicolumn{6}{|c|}{ Family history of HTN } \\
\hline No & 1333 & 16.1 & \multirow{2}{*}{0.0019} & 1 (ref) & \\
\hline Yes & 355 & 24.3 & & $1.77(1.24-2.53)$ & 0.0020 \\
\hline
\end{tabular}

both hypertensive and nonhypertensive women but no significant associations between DASH diet food groups and HTN were found.

Our study showed that approximately one Tunisian woman out of five was hypertensive. This is lower than the prevalence of $36.1 \%$ previously reported by Allal-Elasmi et al. (2012) [32] in the same sampling area. The difference in the age groups of both studied populations (35-69y [32] vs. 25-49y in our study) could explain such dissimilarity in HTN rates. Age plays an important role in increasing blood pressure, and people aged $50 \mathrm{y}$ and over have markedly high risks of cardiovascular disease (CVD) due to HTN [33-35]. This hypothesis is confirmed by previous studies on Tunisian population, where the prevalence of HTN was $4.7 \%$ among adolescent [36] and 55.5\% among elderly women [37]. Compared to studies conducted in other African countries, with an overall mean age close to ours, the prevalence of HTN among women is similar to those reported in Chad $(21.8 \%)$ and Uganda (21.7\%) countries [38, 39]. Higher amounts were recorded from Ghana (28.1\%) [40] and Togo (27.6\%) nations [41]. Generally, the prevalence of HTN among Tunisian women is within the range of $[18.7 \%$ 36.4\%] recorded in Middle East and North Africa (MENA) region, representing the lowest estimates of HTN in middleand low-income countries in the world [4].

In our survey, almost thirty percent of hypertensive women were aware of their condition. Higher rates were previously reported from adults $(44.8 \%$ and $41.0 \%)$ and elderly (81.0\%) living in Tunisian country [37, 42, 43]. The mean age of subjects, which was the lowest in our study, could be the main cause of variability in HTN awareness. Treatment of HTN was achieved by almost two-thirds of women who were aware of their hypertensive status. This relatively elevated rate could be attributed to the availability of free government-supplied antihypertensive drugs distributed in Tunisian hospitals.

In this study, obesity (BMI above $30 \mathrm{~kg} / \mathrm{m}^{2}$ ) and abdominal obesity (WC above $102 \mathrm{~cm}$ ) were among the most influencing factors on blood pressure in Tunisian women. Moreover, salt consumption was significantly higher among hypertensive women. These results suggest that caloric intake but also nutrient composition, especially sodium content, may have an influence on the evolution of blood pressure.

Many mechanisms have been proposed to explain the correlation between obesity and HTN. These mechanisms are largely influenced by the type of adipose tissue and its distribution. Thus, subjects with morbid obesity present an amplified risk of HTN compared to overweight or normal weight persons. At the same time, any loss of weight results in a regression of blood pressure, even in normotensive obese [44]. The association between WC and HTN has been accorded to hyperinsulinemia due to excess abdominal fat [45]. As regards salt intake, there is strong evidence suggesting that a high-salt diet is a major factor increasing blood pressure [46-48]. Large amounts of salt reduce the kidney's ability to evacuate sodium and therefore cause a rise in blood pressure [49]. Furthermore, salt has other harmful effects, independent of and sometimes additive to its influence on blood pressure, such as its association with obesity through soft drink intake [50]. Our findings are in line with those reported by Bruno et al. (2016) [51], who stated that body weight and dietary habits are the main factors influencing blood pressure in a cohort of Italian young adults. Other national investigations, conducted in Tunisia or elsewhere, reported comparable findings [36, 43, 52, 53].

Parity has a strong positive effect on HTN as well as family history of HTN. These results are consistent with those reported in previous research studies. According to Taylor et al. (2008), the number of pregnancies and the parental history of HTN may influence the risk for developing HTN during lifetime [54]. Moreover, the same authors found a statistically significant difference between the number of children and systolic blood pressure in West African Dogon Women [55]. Giubertoni et al. (2013) suggested that women with at least one child had almost threefold risk of being hypertensive in comparison with nulliparous women [56]. This correlation between parity and HTN was attributed to physiological changes in blood perfusion during pregnancy, including increases in cardiac output and blood volume and decreases in systemic and pulmonary vascular resistance [57]. Pregnancy-related weight gain could also be associated with increases in blood pressure $[54,56]$. As regards family history, it is well established that this factor is a strong predictor of HTN contributing to about $30 \%$ of blood pressure variance [58]. Then, studying family history of HTN may be an important strategy for the prevention and control of HTN.

In the present study, at least $60 \%$ of childbearing age Tunisian women met the DASH diet guidelines for total grain, meats, nuts, fats, and sweets. However, the consumption of vegetables, fruits, dairy products, and sodium did not comply with DASH diet pattern. The mean DASH diet 
TABLE 2: Distribution and scoring of the DASH diet index among hypertensive and nonhypertensive women.

\begin{tabular}{|c|c|c|c|c|c|c|}
\hline \multirow[t]{2}{*}{ Dash guideline } & \multirow[t]{2}{*}{ Score } & \multicolumn{2}{|c|}{$\begin{array}{c}\text { Hypertensive } \\
(N=349)\end{array}$} & \multicolumn{2}{|c|}{$\begin{array}{c}\text { Nonhypertensive } \\
\quad(N=1340)\end{array}$} & \multirow[t]{2}{*}{$P$ value } \\
\hline & & $N$ & $\%$ & $N$ & $\%$ & \\
\hline \multicolumn{7}{|l|}{ Total grain } \\
\hline$\geq 7$ servings/day & 1 & 285 & 81.6 & 955 & 71.5 & 0.0078 \\
\hline 5-6 servings/day & 0.5 & 50 & 14.6 & 283 & 21.7 & \\
\hline$<5$ servings/day & 0 & 14 & 03.8 & 102 & 06.8 & \\
\hline \multicolumn{7}{|l|}{ Vegetables } \\
\hline$\geq 4$ servings/day & 1 & 26 & 06.4 & 75 & 05.6 & 0.0544 \\
\hline 2-3 servings/day & 0.5 & 138 & 40.2 & 463 & 33.5 & \\
\hline$<2$ servings/day & 0 & 185 & 53.4 & 802 & 60.9 & \\
\hline \multicolumn{7}{|l|}{ Fruits } \\
\hline$\geq 4$ servings/day & 1 & 13 & 03.4 & 58 & 04.7 & 0.4417 \\
\hline 2-3 servings/day & 0.5 & 55 & 15.9 & 191 & 13.9 & \\
\hline$<2$ servings/day & 0 & 281 & 80.7 & 1091 & 81.5 & \\
\hline \multicolumn{7}{|l|}{ Dairy foods } \\
\hline$\geq 2$ servings/day & 1 & 11 & 03.2 & 61 & 04.9 & 0.4266 \\
\hline 1 serving/day & 0.5 & 50 & 13.5 & 193 & 13.9 & \\
\hline$<1$ serving/day & 0 & 288 & 83.4 & 1086 & 81.5 & \\
\hline \multicolumn{7}{|l|}{ Meats, poultry, and fish } \\
\hline$\leq 2$ servings/day & 1 & 343 & 98.6 & 1308 & 97.6 & 0.3914 \\
\hline 3 servings/day & 0.5 & 0 & 00.0 & 1 & 00.0 & \\
\hline$\geq 4$ servings/day & 0 & 6 & 01.4 & 31 & 02.4 & \\
\hline \multicolumn{7}{|c|}{ Nuts, seeds, and dry beans } \\
\hline$\geq 4$ servings/week & 1 & 226 & 66.0 & 818 & 61.0 & 0.2653 \\
\hline $2-3$ servings/week & 0.5 & 110 & 30.3 & 456 & 34.1 & \\
\hline$<2$ servings/week & 0 & 13 & 03.7 & 66 & 04.8 & \\
\hline \multicolumn{7}{|l|}{$\%$ kcal from fat } \\
\hline$\leq 30 \%$ & 1 & 258 & 73.6 & 963 & 71.5 & 0.8004 \\
\hline $31 \%-32 \%$ & 0.5 & 30 & 08.8 & 125 & 09.5 & \\
\hline$\geq 33 \% 0$ & 0 & 61 & 17.6 & 252 & 18.9 & \\
\hline \multicolumn{7}{|c|}{$\%$ kcal from saturated fatty acids } \\
\hline$\leq 10 \%$ & 1 & 333 & 95.2 & 1240 & 92.2 & 0.1908 \\
\hline $11 \%-12 \%$ & 0.5 & 7 & 02.1 & 49 & 03.6 & \\
\hline$\geq 13 \%$ & 0 & 9 & 02.7 & 51 & 04.2 & \\
\hline \multicolumn{7}{|l|}{ Sweets } \\
\hline$\leq 5$ servings/week & 1 & 241 & 68.8 & 1028 & 77.0 & 0.0120 \\
\hline 6-7 servings/week & 0.5 & 66 & 19.2 & 176 & 13.4 & \\
\hline$\geq 8$ servings/week & 0 & 42 & 12.1 & 136 & 09.6 & \\
\hline \multicolumn{7}{|l|}{ Sodium } \\
\hline$\leq 1500 \mathrm{mg} /$ day & 1 & 1 & 00.3 & 2 & 00.2 & 0.0238 \\
\hline $1501-2400 \mathrm{mg} /$ day & 0.5 & 19 & 05.4 & 142 & 11.2 & \\
\hline$\geq 2401 \mathrm{mg} /$ day & 0 & 329 & 94.3 & 1196 & 88.7 & \\
\hline
\end{tabular}

accordance score of Tunisian women was relatively high compared to data recorded elsewhere [24, 59]. This is probably due to the dietary habits of Tunisian population. Tunisia is a typical country of the MENA region that is undergoing a nutritional and epidemiological transition. This transition was accompanied with a change in food consumption and trade by an increase of cereals, oils, and sugar importation [60]. Intake of vegetables and fruits has also increased leading to the improvement of food diversification in Tunisia. No statistical differences were observed between hypertensive and nonhypertensive women on the adherence to the DASH diet guidelines. However, hypertensive women had a significantly higher intake of total grains, sodium, and sweets than nonhypertensive women. Consequently, they 
were less likely to follow a healthy diet compared to those without HTN diagnosis. Results on multivariable regression analysis showed no association between HTN and DASH diet food groups. This is consistent with the findings of Harrington et al. (2013), who examined the relationship between individual DASH components and systolic blood pressure in older Irish men and women and did not found statistical associations except for low fat milk [17].

\section{Conclusion}

In this study, almost one Tunisian woman out of five was hypertensive. Age, family history, parity, abdominal fat, and BMI status were found as risk factors for HTN. Adherence to DASH diet score by Tunisian women was relatively high compared to data recorded elsewhere and similar between hypertensive and nonhypertensive subjects. The multivariable regression analysis revealed no relationships between HTN and DASH diet food groups. This study, carried out during the period of nutrition transition that occurred in Tunisia, provides a baseline for implemented governmental policies to tackle chronic noncommunicable disease.

\section{Data Availability}

Data are available from the corresponding author upon a reasonable request.

\section{Conflicts of Interest}

The authors declare no conflicts of interest

\section{Acknowledgments}

This study was supported by the CORUS programme of the French Ministry of Overseas and European Affairs, as part of the "Obe-Maghreb" Research Project (Contract Corus 60282); Institut de Recherche pour le Développement (IRD), France; and The National Institute of Nutrition and Food Technology (INNTA), Tunisia.

\section{References}

[1] WHO, Noncommunicable diseases country profiles 2018, World Health Organization, Geneva, 2018.

[2] WHO, Panorama mondial de l' Hypertension. Un «tueur silencieux " responsable d'une crise de santé publique mondiale, World Health Organization, Genoa, Switzerland, 2013.

[3] D. Adeloye and C. Basquill, "Estimating the prevalence and awareness rates of hypertension in Africa: a systematic analysis," PLoS One, vol. 9, no. 8, 2014.

[4] A. M. Sarki, C. U. Nduka, S. Stranges, N. B. Kandala, and O. A. Uthman, "Prevalence of hypertension in low- and middleincome countries: a systematic review and meta-analysis," Medicine, vol. 94, 2015.

[5] O. M. Akpa, F. Made, A. Ojo et al., "Regional patterns and association between obesity and hypertension in Africa: evidence from the H3Africa CHAIR study," Hypertension, vol. 75 , pp. 1167-1178, 2020 .
[6] G. B. D. D. Collaborators, "Health effects of dietary risks in 195 countries, 1990-2017: a systematic analysis for the Global Burden of Disease Study 2017," Lancet, vol. 393, no. 10184, pp. 1958-1972, 2019.

[7] F. M. Sacks, L. P. Svetkey, W. M. Vollmer et al., "Effects on blood pressure of reduced dietary sodium and the Dietary Approaches to Stop Hypertension (DASH) Diet," The New England Journal of Medicine, vol. 344, no. 1, pp. 3-10, 2001.

[8] P. Saneei, A. Salehi-Abargouei, A. Esmaillzadeh, and L. Azadbakht, "Influence of Dietary Approaches to Stop Hypertension (DASH) diet on blood pressure: a systematic review and meta-analysis on randomized controlled trials," Nutrition, Metabolism, and Cardiovascular Diseases, vol. 24, pp. 1253-1261, 2014.

[9] L. Chiavaroli, E. Viguiliouk, S. K. Nishi et al., "DASH dietary pattern and cardiometabolic outcomes: an umbrella review of systematic reviews and meta-analyses," Nutrients, vol. 11, 2019.

[10] S. Soltani, T. Arablou, A. Jayedi, and A. Salehi-Abargouei, "Adherence to the dietary approaches to stop hypertension (DASH) diet in relation to all-cause and cause-specific mortality: a systematic review and dose-response meta-analysis of prospective cohort studies," Nutrition Journal, vol. 19, p. 37, 2020.

[11] UNPD, Human Development Report 2016. Human development for everyone, United Nations Development Program, New York, USA, 2016.

[12] J. El Ati, P. Traissac, F. Delpeuch et al., "Gender obesity inequities are huge but differ greatly according to environment and socio-economics in a North African setting: a national crosssectional study in Tunisia," PLoS One, vol. 7, no. 10, 2012.

[13] P. Traissac, J. El Ati, A. Gartner, H. Ben Gharbia, and F. Delpeuch, "Gender inequalities in excess adiposity and anaemia combine in a large double burden of malnutrition gap detrimental to women in an urban area in North Africa," Public Health Nutrition, vol. 19, pp. 1428-1437, 2016.

[14] M. M. Abassi, S. Sassi, J. El Ati, H. Ben Gharbia, F. Delpeuch, and P. Traissac, "Gender inequalities in diet quality and their socioeconomic patterning in a nutrition transition context in the Middle East and North Africa: a cross-sectional study in Tunisia," Nutrition Journal, vol. 18, no. 1, 2019.

[15] O. Saidi, M. O'Flaherty, N. B. Mansour et al., "Forecasting Tunisian type 2 diabetes prevalence to 2027: validation of a simple model," BMC Public Health, vol. 15, no. 1, 2015.

[16] B. T. Joyce, D. Wu, L. Hou et al., "DASH diet and prevalent metabolic syndrome in the Hispanic Community Health Study/Study of Latinos," Preventive Medical Reports, vol. 15, p. 100950, 2019.

[17] J. M. Harrington, A. P. Fitzgerald, P. M. Kearney et al., "DASH diet score and distribution of blood pressure in middle-aged men and women," American Journal of Hypertension, vol. 26, pp. 1311-1320, 2013.

[18] L. J. Appel, M. W. Brands, S. R. Daniels et al., "Dietary approaches to prevent and treat hypertension: a scientific statement from the American Heart Association," Hypertension, vol. 47, pp. 296-308, 2006.

[19] WHO, Hypertension control: report of a WHO Expert Commitee. WHO technical report studies; 862, World Health Organization, Geneva, 1996.

[20] T. Baranowski, "24-hour recall and diet record methods," in Nutritional Epidemiology, W. Willett, Ed., pp. 46-69, Oxford University Press, Oxford, England, 2012. 
[21] S. Hercberg, M. Deheeger, and P. Preziosi, SU.VI.MAX: Portions alimentaires: Manuel Photos pour l'estimation des quantités, Polytechnia, Paris, France, 2002.

[22] E. Jones-McLean, J. Hu, L. S. Greene-Finestone, and M. de Groh, "A DASH dietary pattern and the risk of colorectal cancer in Canadian adults," Health promotion and chronic disease prevention in Canada: research, policy and practice, vol. 35, pp. 12-20, 2015.

[23] A. R. Folsom, E. D. Parker, and L. J. Harnack, "Degree of concordance with DASH diet guidelines and incidence of hypertension and fatal cardiovascular disease," American Journal of Hypertension, vol. 20, pp. 225-232, 2007.

[24] H. S. Lee, K. B. Lee, Y. Y. Hyun, Y. Chang, S. Ryu, and Y. Choi, "DASH dietary pattern and chronic kidney disease in elderly Korean adults," European Journal of Clinical Nutrition, vol. 71, pp. 755-761, 2017.

[25] H. Reinivuo and K. Laitinen, "Proposal for the harmonization of recipe calculation procedures," European food information resource network, 2007.

[26] J. El Ati, C. Béji, A. Farhat et al., Table de composition des aliments tunisiens Tunis, INNTA (National Institute of Nutrition of Tunisia), Tunisia, 2007.

[27] Agriculture, U.D.O, National nutrient database for standard reference. Release 21, Laboratory, N.D, 2008.

[28] ESHA, Food Processor Software Version 8.3, ESHA Research Inc, Salem, Oregon, USA, 2003.

[29] J. J. Rhee, L. Sampson, E. Cho, M. D. Hughes, F. B. Hu, and W. C. Willett, "Comparison of methods to account for implausible reporting of energy intake in epidemiologic studies," American Journal of Epidemiology, vol. 181, pp. 225-233, 2015.

[30] WHO, Obesity: Preventing and Managing the Global Epidemic, Report of a WHO Consultation, World Health Organization, Geneva, 2000.

[31] J. El Ati, L. Houti, A. Farhat et al., "Development, reproducibility and validity of a physical activity frequency questionnaire in North Africa," Arab Journal of Food and Nutrition, vol. 5, pp. 148-167, 2004.

[32] M. Allal-Elasmi, M. Feki, Y. Zayani et al., "Prehypertension among adults in Great Tunis region (Tunisia): a populationbased study," Pathologie-Biologie, vol. 60, pp. 174-179, 2012.

[33] P. Lloyd-Sherlock, J. Beard, N. Minicuci, S. Ebrahim, and S. Chatterji, "Hypertension among older adults in low- and middle-income countries: prevalence, awareness and control," International Journal of Epidemiology, vol. 43, pp. 116-128, 2014.

[34] S. Ravi, O. I. Bermudez, V. Harivanzan et al., "Sodium intake, blood pressure, and dietary sources of sodium in an adult south Indian population," Annals of Global Health, vol. 82, pp. 234-242, 2016.

[35] S. W. Asgedom, E. K. Gudina, and T. A. Desse, "Assessment of blood pressure control among hypertensive patients in Southwest Ethiopia," PLoS One, vol. 11, no. 11, 2016.

[36] H. Aounallah-Skhiri, J. El Ati, P. Traissac et al., "Blood pressure and associated factors in a North African adolescent population. A national cross-sectional study in Tunisia," BMC public health, vol. 12, no. 1, 2012.

[37] S. Hammami, S. Mehri, S. Hajem et al., "Awareness, treatment and control of hypertension among the elderly living in their home in Tunisia," BMC Cardiovascular Disorders, vol. 11, no. $1,2011$.

[38] M. Dionadji, B. Boy, M. Mouanodji, and G. Batakao, "Prevalence of diabetes mellitus in rural areas in Chad," Medecine tropicale: revue du Corps de sante colonial, vol. 70, pp. 414415, 2010.

[39] G. Musinguzi and F. Nuwaha, "Prevalence, awareness and control of hypertension in Uganda," PLoS One, vol. 8, no. 4, 2013.

[40] C. Agyemang, "Rural and urban differences in blood pressure and hypertension in Ghana, West Africa," Public Health, vol. 120, no. 6, pp. 525-533, 2006.

[41] S. Baragou, M. Djibril, B. Atta, F. Damorou, M. Pio, and A. Balogou, "Prevalence of cardiovascular risk factors in an urban area of Togo: a WHO STEPS-wise approach in Lome, Togo," Cardiovascular Journal of Africa, vol. 23, no. 6, pp. 309-312, 2012.

[42] H. Ben Romdhane, H. Skhiri, S. Bougatef et al., "Hypertension prevalence, awareness, treatment and control: results from a community based survey," La Tunisie medicale, vol. 83, Supplement 5, pp. 41-46, 2005.

[43] H. Ben Romdhane, S. Ben Ali, H. Skhiri et al., "Hypertension among Tunisian adults: results of the TAHINA project," Hypertension research: official journal of the Japanese Society of Hypertension, vol. 35, pp. 341-347, 2012.

[44] G. de Simone, C. Mancusi, R. Izzo, M. A. Losi, and L. Aldo Ferrara, "Obesity and hypertensive heart disease: focus on body composition and sex differences," Diabetology \& Metabolic Syndrome, vol. 8, p. 79, 2016.

[45] S. Lee, F. Bacha, and S. A. Arslanian, "Waist circumference, blood pressure, and lipid components of the metabolic syndrome," The Journal of Pediatrics, vol. 149, pp. 809-816, 2006.

[46] F. J. He, M. Burnier, and G. A. Macgregor, "Nutrition in cardiovascular disease: salt in hypertension and heart failure," European Heart Journal, vol. 32, no. 24, pp. 3073-3080, 2011.

[47] T. M. Frisoli, R. E. Schmieder, T. Grodzicki, and F. H. Messerli, "Salt and hypertension: is salt dietary reduction worth the effort?," The American Journal of Medicine, vol. 125, no. 5, pp. 433-439, 2012.

[48] F. J. He and G. A. MacGregor, "A comprehensive review on salt and health and current experience of worldwide salt reduction programmes," Journal of Human Hypertension, vol. 23, pp. 363-384, 2009.

[49] R. P. Lifton, A. G. Gharavi, and D. S. Geller, "Molecular mechanisms of human hypertension," Cell, vol. 104, no. 4, pp. 545556, 2001.

[50] L. R. Vartanian, M. B. Schwartz, and K. D. Brownell, "Effects of soft drink consumption on nutrition and health: a systematic review and meta-analysis," American Journal of Public Health, vol. 97, pp. 667-675, 2007.

[51] R. M. Bruno, G. Pucci, M. Rosticci et al., “Association between lifestyle and systemic arterial hypertension in young adults: a national, survey-based, cross-sectional study," High blood pressure \& cardiovascular prevention: the official journal of the Italian Society of Hypertension, vol. 23, pp. 31-40, 2016.

[52] K. M. Saeed, "Burden of hypertension in the Capital of Afghanistan: a cross-sectional study in Kabul City, 2015," International Journal of Hypertension, vol. 2017, Article ID 3483872, 7 pages, 2017.

[53] V. M. Oguoma, E. U. Nwose, T. C. Skinner, K. A. Digban, I. C. Onyia, and R. S. Richards, "Prevalence of cardiovascular disease risk factors among a Nigerian adult population: relationship with income level and accessibility to CVD risks screening," BMC Public Health, vol. 15, no. 1, 2015.

[54] J. Y. Taylor, A. N. Chambers, B. Funnell, and C. Y. Wu, "Effects of parity on blood pressure among African- 
American women," Journal of National Black Nurses' Association: JNBNA, vol. 19, pp. 12-19, 2008.

[55] J. Y. Taylor, D. A. Sampson, C. M. Anderson, D. Caldwell, and A. D. Taylor, "Effects of parity on blood pressure among West African Dogon women," Ethnicity \& Disease, vol. 22, pp. 360366, 2012.

[56] E. Giubertoni, L. Bertelli, Y. Bartolacelli, G. Origliani, and M. G. Modena, "Parity as predictor of early hypertension during menopausal transition," Journal of Hypertension, vol. 31, no. 3, pp. 501-507, 2013.

[57] E. P. Gunderson, V. Chiang, C. E. Lewis et al., "Long-term blood pressure changes measured from before to after pregnancy relative to nonparous women," Obstetrics and Gynecology, vol. 112, pp. 1294-1302, 2008.

[58] P. Corvol, X. Jeunemaitre, A. Charru, and F. Soubrier, "Can the genetic factors influence the treatment of systemic hypertension? The case of the renin-angiotensin-aldosterone system," The American Journal of Cardiology, vol. 70, no. 12, pp. D14-D20, 1992.

[59] D. E. Epstein, A. Sherwood, P. J. Smith et al., "Determinants and consequences of adherence to the dietary approaches to stop hypertension diet in African-American and white adults with high blood pressure: results from the ENCORE trial," Journal of the Academy of Nutrition and Dietetics, vol. 112, no. 11, pp. 1763-1773, 2012.

[60] NIS, Statistical Yearbook of Tunisia 2014-2018, National Institue of Statistics, Tunisia, 2019. 